\title{
Evaluation of patient-centered outcomes associated with the acceleration of canine retraction by using minimally invasive surgical procedures: A randomized clinical controlled trial
}

\section{Ocena korzyści pacjenta związanych z akceleracją cofania kłów po zastosowaniu minimalnie inwazyjnych technik chirurgicznych - randomizowane badanie kliniczne z grupą kontrolną} \author{
Bassel Brad ${ }^{3, A, D-F}$, Youssef Latifeh ${ }^{4,-F}$ \\ ${ }^{1}$ Department of Orthodontics, Dental School, University of Damascus, Syria \\ ${ }^{2}$ Department of Oral Medicine, Dental School, University of Damascus, Syria \\ ${ }^{3}$ Department of Oral and Maxillofacial Surgery, Dental School, University of Damascus, Syria \\ ${ }^{4}$ Department of Psychiatry, Faculty of Medicine, University of Damascus, Syria \\ A - research concept and design; $\mathrm{B}$ - collection and/or assembly of data; $\mathrm{C}$ - data analysis and interpretation; \\ $D$ - writing the article; $E$ - critical revision of the article; $F$ - final approval of the article
}

Alaa Mohammad Haytham Alfawal ${ }^{1, A, B, D,-F}$, Mohammad Younis Hajeer, ${ }^{1, A, C F}$, Mowaffak Ahmad Ajaj ${ }^{1, A, D-F}$, Omar Hamadah ${ }^{2, A, D-F}$,

Address for correspondence

Mohammad Younis Hajeer

E-mail: myhajeer@gmail.com

Funding sources

This work was supported by the University of Damascus Postgraduate Research Budget (Ref. No. 83054206791DEN).

Conflict of interest

None declared

Received on August 15, 2019

Reviewed on January 10, 2020

Accepted on April 7, 2020

Published online on September 10, 2020

Cite as

Alfawal AMH, Hajeer MY, Mowaffak AA, Hamadah 0, Brad B, Latifeh $Y$. Evaluation of patient-centered outcomes associated with the acceleration of canine retraction by using minimally invasive surgical procedures: A randomized clinical controlled trial. Dent Med Probl. 2020;57(3):285-293. doi:10.17219/dmp/120181

DOI

$10.17219 / \mathrm{dmp} / 120181$

Copyright

( 2020 by Wroclaw Medical University

This is an article distributed under the terms of the

Creative Commons Attribution 3.0 Unported License (CC BY 3.0)

(https://creativecommons.org/licenses/by/3.0/).

\begin{abstract}
Background. Only a few studies in the literature have reported patient-centered outcomes associated with minimally invasive corticotomy, and thus, related scientific evidence is limited.

Objectives. The objective of this study was to evaluate patient-centered outcomes associated with upper canine retraction assisted with piezocision or laser-assisted flapless corticotomy (LAFC).

Material and methods. Thirty-two patients ( 19 females, 13 males) at a mean age of $18.25 \pm 3.05$ years were randomly divided into 2 equal groups: the LAFC group (LG; $n=16)$ and the piezocision group (PG; $n=16)$. In each group, the surgical procedure was randomly assigned to one side of the maxillary arch, and the other side served as the control. Standardized questionnaires using the numerical rating scale (NRS) were distributed to all patients during the $1^{\text {5t }}$ month after the surgical procedure at 4 time points: $24 \mathrm{~h}$ (T1); 3 days (T2); 7 days (T3); and 14 days (T4). The patients' responses were obtained, regarding their feelings of pain, discomfort, swelling, eating difficulty, Jaw movement restriction, analgesic consumption, and satisfaction.
\end{abstract}

Results. The levels of pain, discomfort, swelling, and difficulty in chewing were significantly greater at the experimental sides as compared to the control sides only at $T 1$ in both groups $(p<0.05)$. The levels of pain and discomfort in LG were significantly lower than those in PG only at $\mathrm{T1}(p=0.013$ and $p=0.009$, respectively) whereas there were no significant differences between the groups regarding swelling, eating difficulty, jaw movement restriction, and analgesic consumption. The patients in both groups reported high levels of satisfaction, with no significant differences. The levels of pain, discomfort, swelling, eating difficulty, and jaw movement restriction were dramatically decreased 1 day after flapless corticotomy treatment in both groups $(p<0.05)$.

Conclusions. Both LAFC and piezocision were associated with high levels of pain, discomfort, swelling, and difficulty in chewing at T1. Laser-assisted flapless corticotomy caused less pain and discomfort than piezocision. 
Key words: piezosurgery, orthodontic tooth movement, minimally invasive surgical procedures, patient-centered care

Słowa kluczowe: piezochirurgia, ortodontyczny ruch zębów, minimalnie inwazyjne techniki chirurgiczne, opieka skoncentrowana na pacjencie

\section{Introduction}

Due to esthetic concerns, the reduction of orthodontic treatment time is considered one of the most important needs of both patients and orthodontists. ${ }^{1}$ Corticotomyassisted orthodontic treatment (CAOT) has been recently introduced as an effective solution for adults who seek accelerated orthodontic tooth movement, ${ }^{2,3}$ but it has not met with general approval from patients because of the aggressive nature of corticotomy, and the attendant anxiety and fear of pain. ${ }^{4}$ Therefore, several forms of minimally invasive corticotomy have been developed as alternative procedures to traditional corticotomy; these procedures do not need the extensive removal of the cortical bone or full mucoperiosteal flaps, and use innovative tools which cause less trauma. One example is piezocision - a minimally invasive procedure introduced in 2009 by Dibart et al. to overcome the disadvantages of corticotomy. ${ }^{5}$ This technique involves performing vertical cuts in the attached gingiva and the alveolar cortical bone without flap elevation using a piezosurgery knife. ${ }^{5}$ It has also been suggested that laser-assisted flapless corticotomy (LAFC) might cause less trauma to hard and soft tissues, and result in fewer complications. ${ }^{6,7}$

One of the most important disadvantages of surgical techniques used to accelerate tooth movement is the patient's pain and discomfort. ${ }^{8}$ Furthermore, studies have shown that pain is considered a deterrent for orthodontic treatment and an important reason to stop it. ${ }^{9}$ It has been claimed that minimally invasive surgical procedures could accelerate orthodontic tooth movement with minimal levels of pain and discomfort, but only a few studies in the literature have reported patient-centered outcomes associated with minimally invasive corticotomy, ${ }^{10}$ and related scientific evidence is limited. ${ }^{11-13}$ Therefore, the aim of the current trial was to evaluate and compare patientcentered outcomes associated with canine retraction accelerated by using piezocision or LAFC.

\section{Material and methods}

\section{Subjects and study design}

The local ethics committee of the Dental School at the University of Damascus in Syria approved the protocol of the current trial (UDDS-372-07042015/SRC-2744). The trial was conducted between February 2017 and December 2018. This study was a compound parallel-group randomized controlled trial. Thirty-two patients were allocated randomly to the LAFC group (LG; $n=16$ ) and the piezocision group (PG; $n=16$ ); then, a split-mouth design was applied in each group so that patients could receive canine retraction facilitated with either LAFC or piezocision at the experimental side, with the contralateral side serving as the control (without any intervention). Computer-generated randomization lists with an allocation ratio 1:1 were created by one of the co-authors (O.H.) using Minitab ${ }^{\circledR}$, v. 17 (Minitab Inc., State College, USA). Allocation was concealed by using a sequentially numbered, opaque, sealed envelope. Blinding was applied only for the outcome assessor, as blinding of the principal researcher and the patients was not possible.

Thirty-two adult patients (19 females, 13 males) at a mean age of $18.25 \pm 3.05$ years who visited the Department of Orthodontics of the Dental School at the University of Damascus, Syria, were recruited into this study. All the patients met the following inclusion criteria: class II division I malocclusion with an indication for the extraction of the upper first premolars (an overjet of 5-10 mm, normal or long face growth patterns); age range between 16 and 29 years; healthy patients with no prior orthodontic treatment; and good oral hygiene (probing depth $\leq 3 \mathrm{~mm}$, no alveolar bone loss assessed radiographically).

The teeth were leveled and aligned using $\mathrm{MBT}^{\mathrm{TM}}$ prescription brackets with 0.022-inch slots (JISCOP Co., Ltd., Gunpo-si, South Korea). The upper first premolars were extracted before the fixed appliances were applied and moderate anchorage (soldered transpalatal arch) was used. After the completion of leveling and alignment, and before canine distalization, flapless corticotomy was performed at the experimental side. Once local anesthesia had taken effect, in PG, 2 vertical incisions, each of a length of $10 \mathrm{~mm}$, were made using a No. 15 blade in the attached gingiva distal to the upper canines; then, cortical incisions were made using a piezosurgery knife (BS1, Piezotome ${ }^{\circledR}$, Implant Center ${ }^{\mathrm{TM}} 2$; Satelec, Mérignac, France) in the alveolar cortical bone with a depth of $3 \mathrm{~mm}$. In LG, an erbium-doped yttrium aluminum garnet (Er:YAG) laser (LightWalker ${ }^{\circledR}$ ST-E; Fotona, Ljubljana, Slovenia) with a R14C handpiece and the Cylindrical Sapphire Tip (diameter: $1.3 \mathrm{~mm}$, length: $8 \mathrm{~mm}$ ) in the non-contact mode was used to perform both gingival and cortical perforations. Five perforations were conducted distal to the upper canines; each perforation was $1.3 \mathrm{~mm}$ wide and away from the other perforation at least $1.5 \mathrm{~mm}$, with a depth of $3 \mathrm{~mm}$. The device settings were as follows: $100 \mathrm{~mJ}, 10 \mathrm{~Hz}$ and $2 \mathrm{~W}$ for soft tissue perforations, and then the settings were changed to $200 \mathrm{~mJ}, 12 \mathrm{~Hz}$ and $3 \mathrm{~W}$ for cortical perforations. No sutures were applied and antibiotics (Augmentin ${ }^{\circledR}$, 625-milligram tablets) were prescribed for 5 days in both groups, ${ }^{14,15}$ although recent guidelines of the American Dental Association (ADA) indicate that it is not necessary 
to administer a prophylactic antibiotic cover following minor surgery in patients with good health and immunity. ${ }^{16}$ The patients were instructed to take analgesics (paracetamol, 500-milligram tablets) only when necessary and at least $6 \mathrm{~h}$ before filling out the questionnaire. The patients were also asked to record and inform the researcher about the number of paracetamol tablets they took.

Canine retraction was initiated immediately on $0.019 \times 0.025$-inch stainless steel (SS) wires using 150 -gram NiTi closed-coil springs and continued until class I relationship was achieved as shown in Fig. 1. The same researcher (A.M.H.A.) treated all patients in both groups.

\section{Questionnaires}

Standardized questionnaires were answered by the patients at chairside as shown in Table 1 . The researcher was present to answer any questions raised by the patients while filling out the questionnaire without affecting their responses. The patients' responses were obtained, regarding their perception of pain, discomfort, swelling, eating difficulty, jaw movement restriction, and analgesic consumption at 4 assessment time points: $24 \mathrm{~h}$ (T1), 3 days (T2), 7 days (T3), and 14 days (T4) after the onset of canine retraction. The patients were also asked about their levels of satisfaction, whether they would advise a friend to undergo the same surgical intervention, and whether the extraction of the premolars or the surgical intervention was the most annoying experience at the end of the canine retraction stage (T5).

The first 10 questions were related to the perception of pain, discomfort, swelling, difficulty in chewing, difficulty in swallowing, and restriction in jaw movement. The patients recorded their responses using the numerical rating scale (NRS), with 0 and 10 placed at the opposite ends of this scale. With regard to pain assessment, the patients were instructed that 0 would mean 'no pain' and 10 would mean 'the worst pain imaginable'.
Table 1. Questions given to the patients at 5 assessment time points

\begin{tabular}{|c|c|}
\hline No. & Question \\
\hline 1 & $\begin{array}{l}\text { Do you have pain in your mouth or teeth } \\
\text { at the surgical intervention side? }\end{array}$ \\
\hline 2 & $\begin{array}{l}\text { Do you have pain in your mouth or teeth } \\
\text { at the non-operated side? }\end{array}$ \\
\hline 3 & $\begin{array}{l}\text { Do you experience discomfort in your mouth or teeth } \\
\text { at the surgical intervention side? }\end{array}$ \\
\hline 4 & $\begin{array}{l}\text { Do you experience discomfort in your mouth or teeth } \\
\text { at the non-operated side? }\end{array}$ \\
\hline 5 & $\begin{array}{l}\text { Do you experience swelling in your mouth } \\
\text { at the surgical intervention side? }\end{array}$ \\
\hline 6 & $\begin{array}{l}\text { Do you experience swelling in your mouth } \\
\text { at the non-operated side? }\end{array}$ \\
\hline 7 & $\begin{array}{l}\text { Do you experience difficulty in chewing food } \\
\text { at the surgical intervention side? }\end{array}$ \\
\hline 8 & $\begin{array}{l}\text { Do you experience difficulty in chewing food } \\
\text { at the non-operated side? }\end{array}$ \\
\hline 9 & Do you experience difficulty in swallowing? \\
\hline 10 & Do you experience restriction in jaw movement? \\
\hline 11 & $\begin{array}{l}\text { Have you used analgesics for pain from your teeth or jaws? } \\
\qquad \text { If yes, what dosage did you use? }\end{array}$ \\
\hline 12 & Are you satisfied with your treatment? \\
\hline 13 & Would you advise a friend to undergo the same treatment? \\
\hline 14 & $\begin{array}{l}\text { What was more disturbing to you - the extraction } \\
\text { of the premolars or the surgical intervention? }\end{array}$ \\
\hline
\end{tabular}

Questions 1-11 were asked at 1 day (T1), 3 days (T2), 7 days (T3), and

14 days (T4) after the onset of canine retraction whereas questions

12-14 were asked at the end of canine retraction (T5).

The same method of recording the patients' experiences on this scale was explained for the rest of the questions. Question 11 was answered with 'yes/no' and a space was provided for writing the amount of consumption in grams. Question 12 was also answered using NRS, but 0 meant 'no satisfaction' and 10 meant 'the best satisfaction'. The questionnaires were analyzed by one of the co-authors (M.A.A.), who was blinded to treatment allocation.

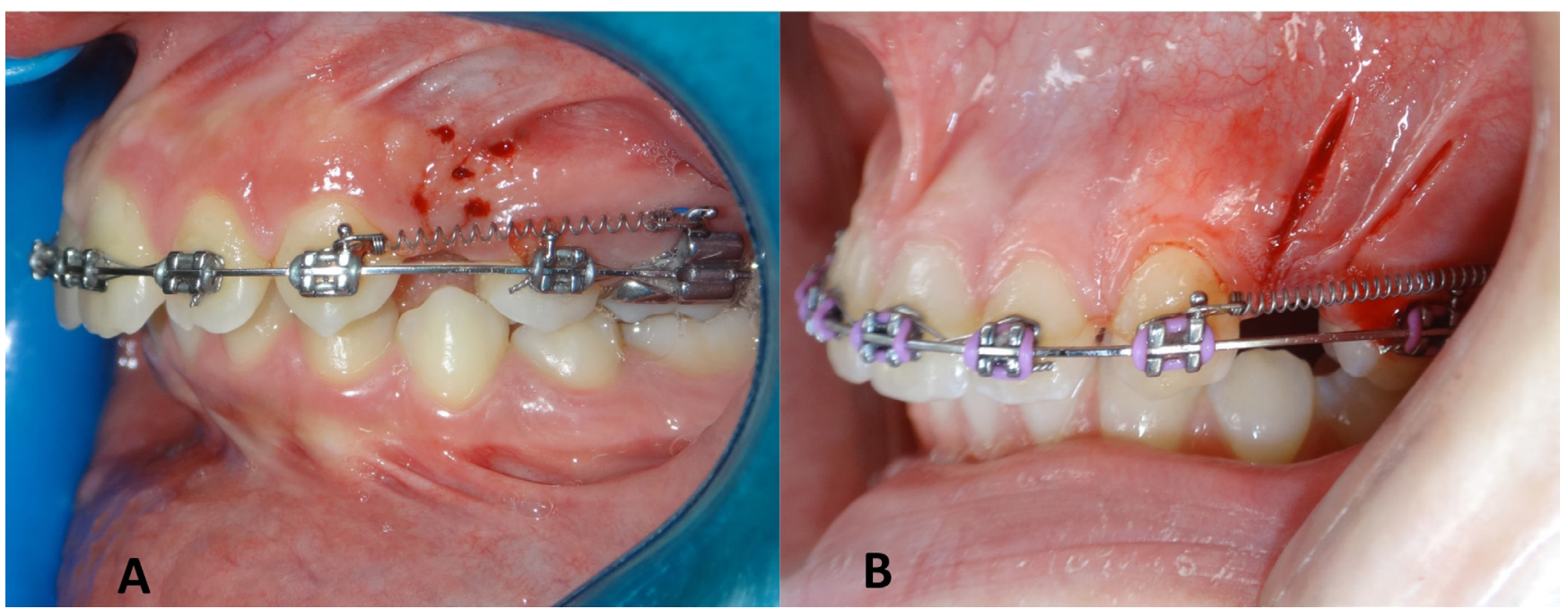

Fig. 1. Canine retraction using NiTi closed-coil springs, facilitated by laser-assisted flapless corticotomy (LAFC) (A) or piezocision (B) 


\section{Statistical analysis}

The Minitab software, v. 17 was used to calculate the sample size and conduct all statistical analyses by one of the co-authors (M.Y.H.), who was blinded to the data collected in the questionnaires.

The non-parametric Wilcoxon signed-rank tests were used to assess differences within each group between the control and experimental sides. The Mann-Whitney $U$ tests were used to detect differences between the 2 groups regarding pain, discomfort, swelling, difficulty in chewing, difficulty in swallowing, restriction in jaw movement, and satisfaction. The $X^{2}$ tests were used to assess differences between the groups concerning the consumption of analgesics, the recommendation of the procedure to a friend, and whether the extraction of the premolars or the surgical intervention was the most disturbing experience. To evaluate changes in the studied variables over time, Friedman's test was used. When a result was significant, the post-hoc Wilcoxon matched-pairs signed-rank tests were employed. Statistical significance was considered when a $p$-value was found less than $5 \%$. For the multiplicity of tests, the Bonferroni correction was employed.

\section{Results}

All patients completed their questionnaires and no patient was lost to follow-up. Consequently, LG involved 16 patients ( 10 females, 6 males) at a mean age of $18.44 \pm 3.38$ years whereas PG involved 16 patients (9 females, 7 males) at a mean age of $18.06 \pm 2.79$ years. There were no significant differences between both group regarding age $(p=0.711)$ and gender $(p=0.719)$. Patient allocation and follow-up are presented in Fig. 2.

\section{Pain and discomfort}

The levels of experienced pain and discomfort were significantly greater at the experimental sides as compared to the control sides at T1 in LG $(p=0.005$ and $p<0.001$, respectively) and also PG ( $p=0.001$ and $p<0.001$, respectively) as shown in Table 2 and Fig. 3.

Then, the levels of pain and discomfort perception greatly decreased at the experimental sides to the extent that the differences between the 2 sides were not significant at T2, T3 and T4 in both groups. The levels

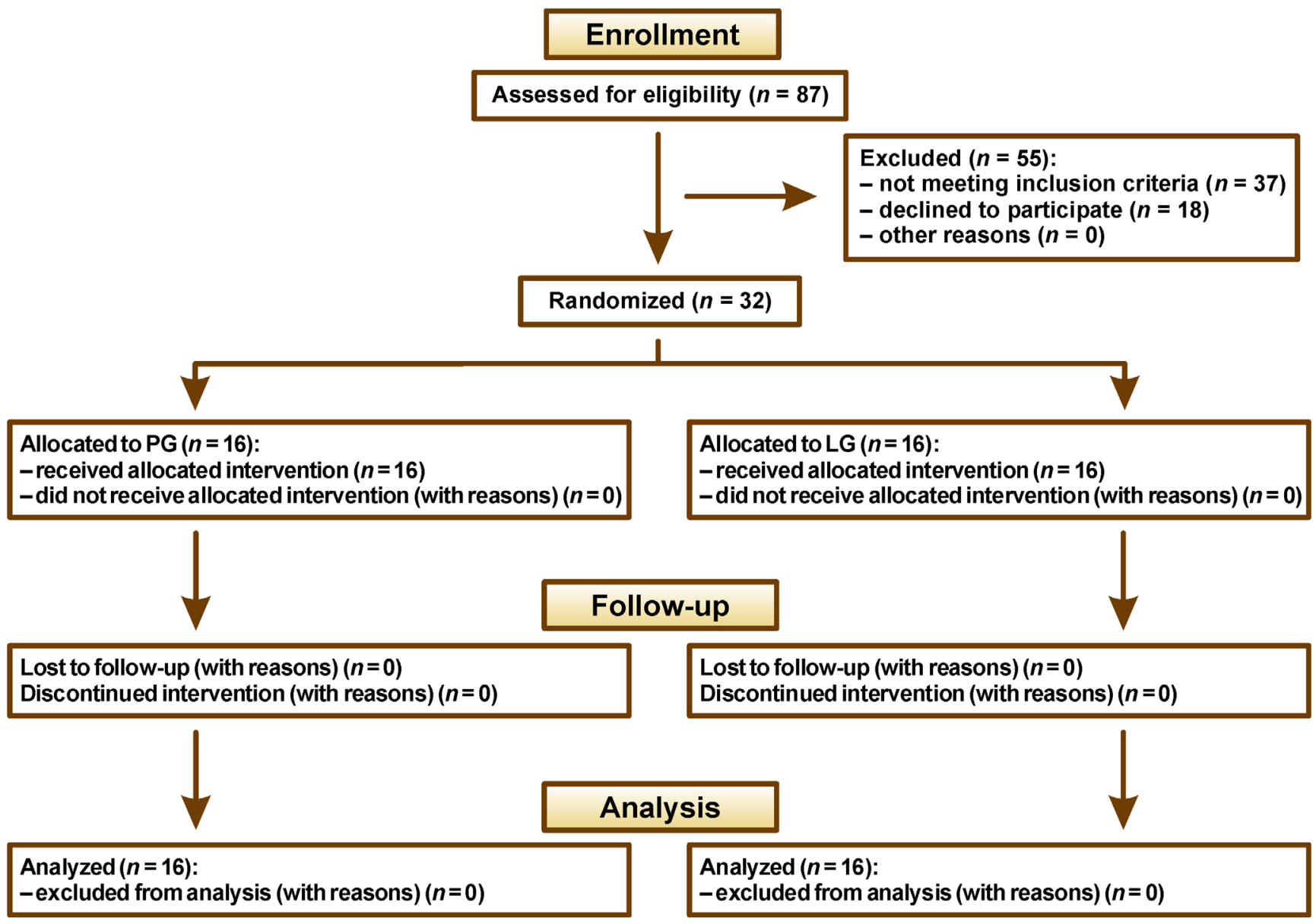

Fig. 2. CONSORT (Consolidated Standards of Reporting Trials) participants'flow diagram

PG - piezocision group; LG - LAFC group. 
of pain and discomfort perception in LG were significantly lower than those in PG only at T1 $(p=0.013$ and $p=0.009$, respectively) whereas there were no significant differences between both groups at the subsequent assessment time points.

\section{Swelling and difficulty in chewing}

The levels of swelling and difficulty in chewing were significantly higher at the experimental sides than in the control sides only at T1 in both groups $(p<0.001)$.

Table 2. Descriptive statistics of the levels of pain, discomfort, swelling, and difficulty in chewing perceived by the patients as well as the $p$-values of significance tests

\begin{tabular}{|c|c|c|c|c|c|c|c|c|c|c|c|c|}
\hline \multirow{3}{*}{$\begin{array}{l}\text { Time } \\
\text { point }\end{array}$} & \multirow{3}{*}{ Variable } & \multicolumn{5}{|c|}{ LG $(n=16)$} & \multicolumn{5}{|c|}{$\mathrm{PG}(n=16)$} & \multirow{3}{*}{$\begin{array}{l}\text { LG vs PG } \\
p \text {-value }{ }^{t t}\end{array}$} \\
\hline & & \multicolumn{2}{|c|}{ experimental side } & \multicolumn{2}{|c|}{ control side } & \multirow{2}{*}{$p$-value ${ }^{\dagger}$} & \multicolumn{2}{|c|}{ experimental side } & \multicolumn{2}{|c|}{ control side } & \multirow{2}{*}{$p$-value ${ }^{\dagger}$} & \\
\hline & & Me & $I Q R$ & Me & $I Q R$ & & Me & $I Q R$ & Me & $I Q R$ & & \\
\hline \multirow{4}{*}{$\mathrm{T} 1$} & pain & 4 & $2-5$ & 2 & $1-2.75$ & $0.005^{*}$ & 5.5 & $4-7$ & 1.5 & $0.25-2.75$ & $0.001^{* *}$ & $0.013^{*}$ \\
\hline & discomfort & 5.5 & $5-7$ & 3 & $2-4$ & $<0.001^{* * *}$ & 8 & $6-9$ & 4 & $3-5$ & $<0.001^{* * *}$ & $0.009^{* *}$ \\
\hline & swelling & 2 & $1.25-3$ & 1 & $0-1$ & $<0.001^{* * *}$ & 3 & $2-4$ & 1 & $0.25-2$ & $<0.001^{* * *}$ & 0.118 \\
\hline & difficulty in chewing & 4 & $3-5$ & 1 & $1-2$ & $<0.001^{* * *}$ & 4.5 & $4-6$ & 2 & $1-3$ & $<0.001^{* * *}$ & 0.082 \\
\hline \multirow{4}{*}{$\mathrm{T} 2$} & pain & 1 & $0-2$ & 1 & $0-1$ & 0.106 & 1.5 & $1-2.75$ & 1 & $0.25-1.75$ & 0.100 & 0.338 \\
\hline & discomfort & 3 & $1.25-4$ & 2 & $1-2.75$ & 0.096 & 3 & $2-4.75$ & 2 & $1-3$ & 0.065 & 0.528 \\
\hline & swelling & 1 & $0-2$ & 0.5 & $0-1$ & 0.070 & 2 & $1-2$ & 1 & $0-2$ & 0.078 & 0.109 \\
\hline & difficulty in chewing & 1 & $0-2$ & 0.5 & $0-1$ & 0.073 & 2 & $0.25-3$ & 1.5 & $0-2$ & 0.119 & 0.194 \\
\hline \multirow{4}{*}{ T3 } & pain & 0 & $0-1$ & 0 & $0-1$ & 0.157 & 1 & $0-1$ & 0 & $0-1$ & 0.157 & 0.695 \\
\hline & discomfort & 0 & $0-1.75$ & 0 & $0-0.75$ & 0.167 & 0 & $0-2$ & 0 & $0-1$ & 0.121 & 0.983 \\
\hline & swelling & 0 & $0-0$ & 0 & $0-0$ & 0.480 & 0 & $0-1$ & 0 & $0-0.75$ & 0.405 & 0.281 \\
\hline & difficulty in chewing & 0 & $0-1$ & 0 & $0-0.75$ & 0.272 & 0.5 & $0-2$ & 0 & $0-1$ & 0.155 & 0.415 \\
\hline \multirow{4}{*}{$\mathrm{T} 4$} & pain & 0 & $0-0$ & 0 & $0-0$ & 0.157 & 0 & $0-0$ & 0 & $0-0$ & 0.317 & 0.632 \\
\hline & discomfort & 0 & $0-0.75$ & 0 & $0-0.75$ & 1.000 & 0 & $0-0.75$ & 0 & $0-0$ & 0.317 & 0.920 \\
\hline & swelling & 0 & $0-0$ & 0 & $0-0$ & 0.317 & 0 & $0-0$ & 0 & $0-0$ & 0.157 & 0.551 \\
\hline & difficulty in chewing & 0 & $0-0.5$ & 0 & $0-0$ & 0.414 & 0 & $0-1$ & 0 & $0-0$ & 0.102 & 0.544 \\
\hline
\end{tabular}

Me - median; IQR - interquartile range; ${ }^{*} p<0.05 ;{ }^{* *} p<0.01 ;{ }^{* * *} p<0.001 ;{ }^{\dagger}$ Wilcoxon signed-rank test; ${ }^{\text {t+ }}$ Mann-Whitney $U$ test.
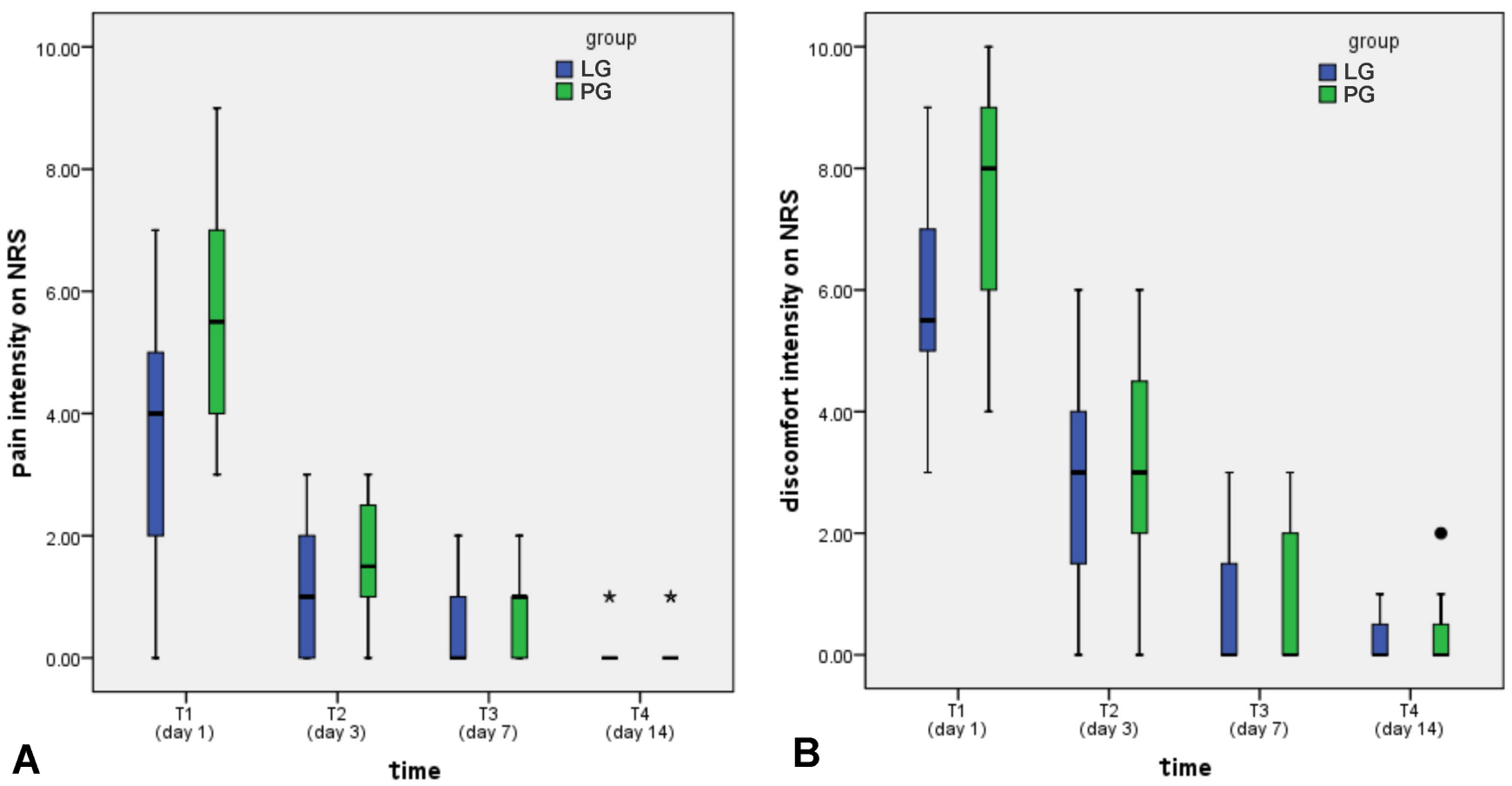

Fig. 3. Box plot showing the levels of pain (A) and discomfort (B) assessed on the numerical rating scale (NRS) in both groups The asterisks indicate extreme outliers whereas dots indicate outliers. 
There were no significant differences between both sides at T2, T3 and T4. There were no significant differences between both groups at all evaluated time points as shown in Table 2 and Fig. 4.

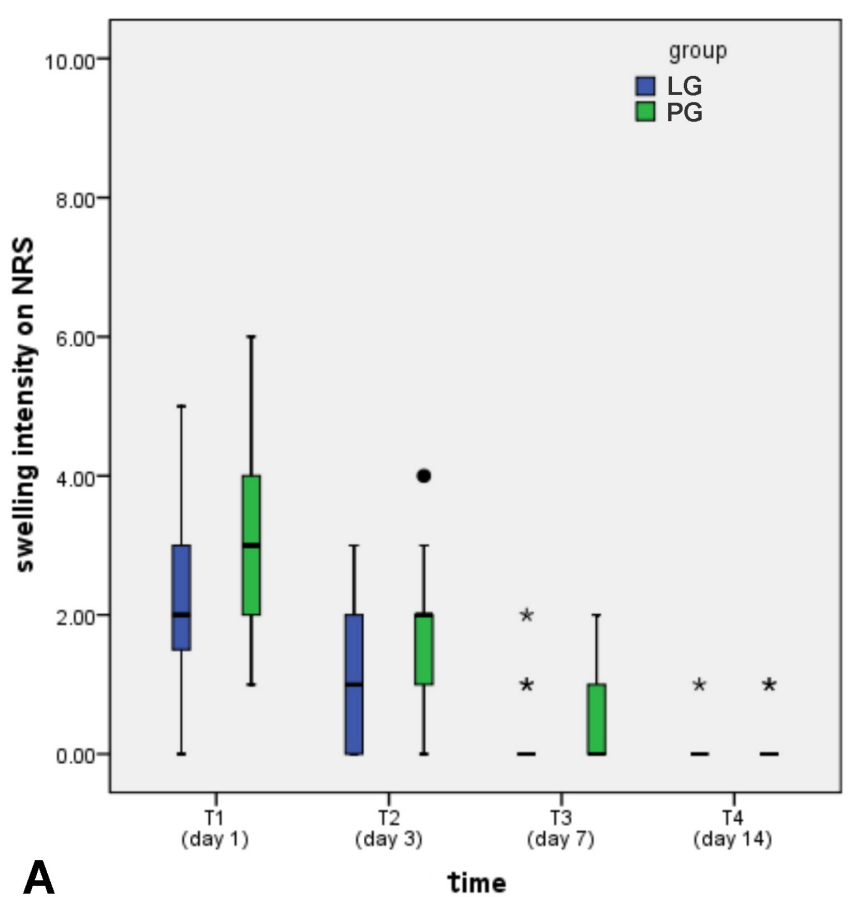

Difficulty in swallowing and jaw movement restriction

There were no significant differences between LG and PG at all evaluated time points (Table 3 and Fig. 5).

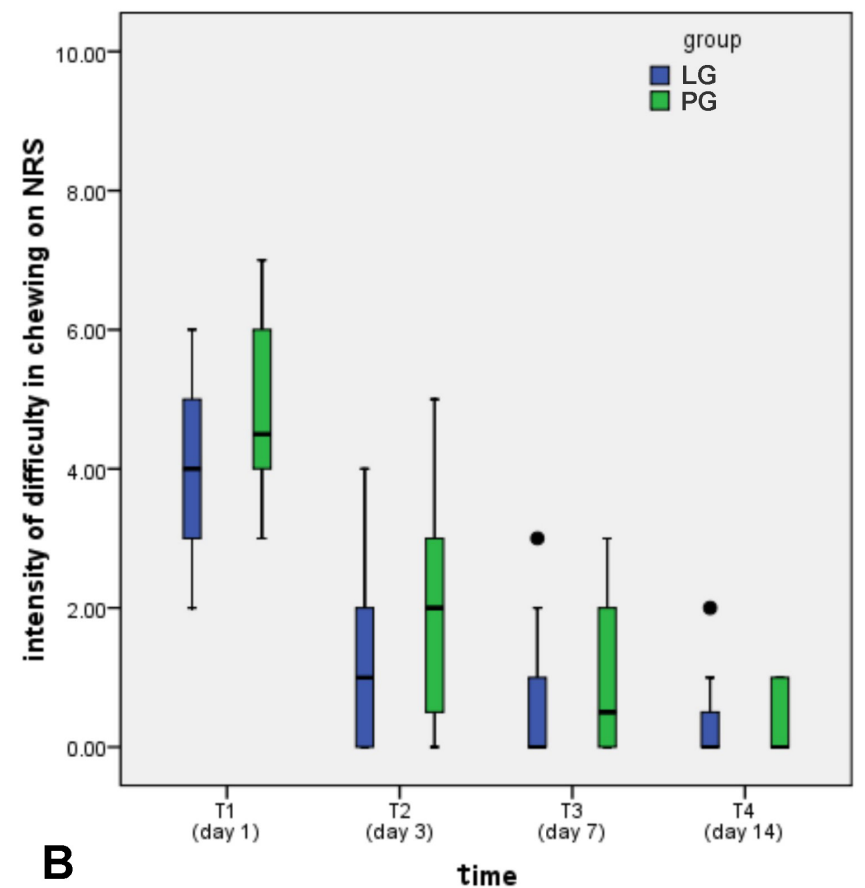

Fig. 4. Box plot showing the levels of swelling (A) and difficulty in chewing (B) assessed on NRS in both groups The asterisks indicate extreme outliers whereas dots indicate outliers.
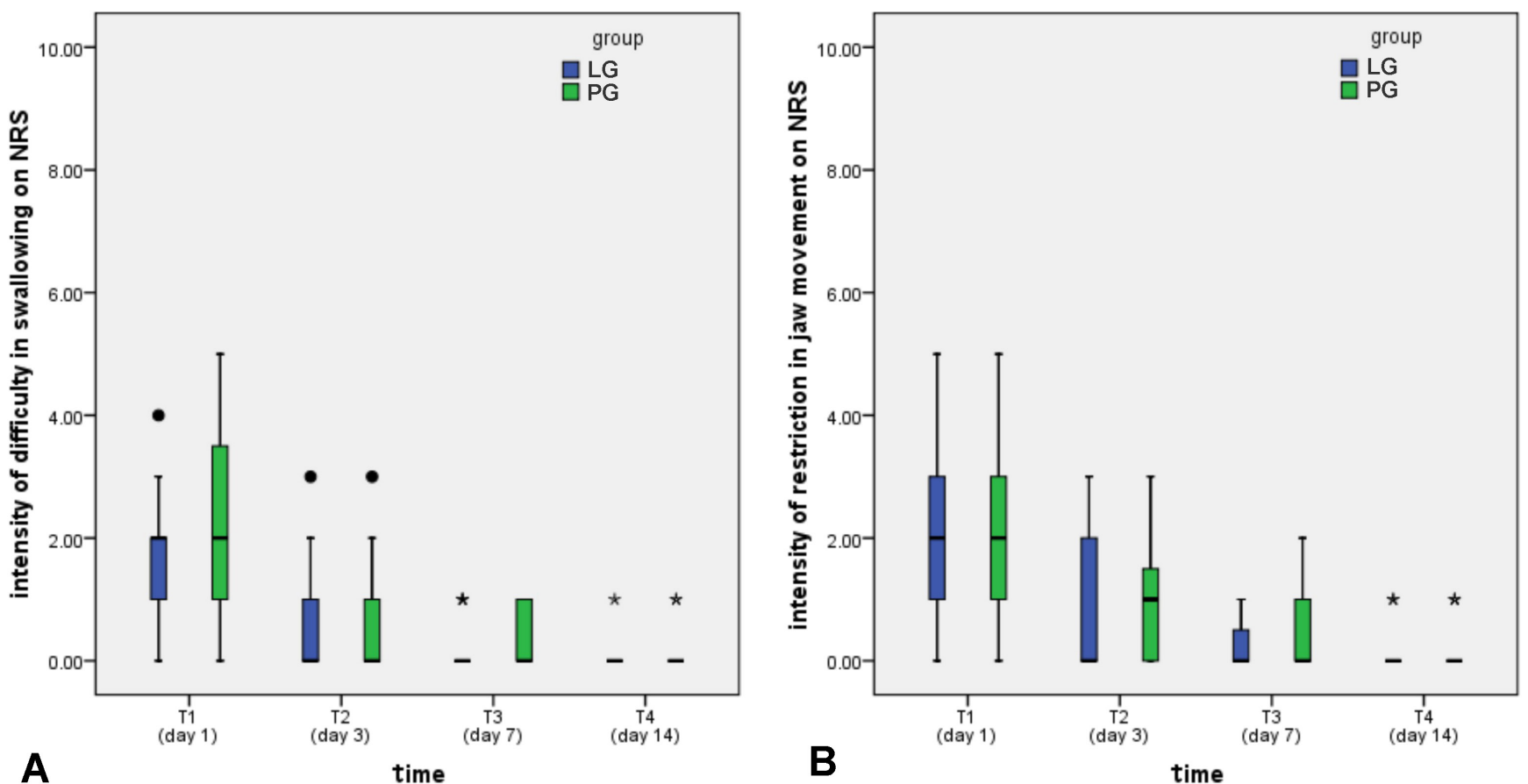

Fig. 5. Box plot showing the levels of difficulty in swallowing (A) and restriction in jaw movements assessed on NRS in both groups The asterisks indicate extreme outliers whereas dots indicate outliers. 
Table 3. Descriptive statistics of the difficulty in swallowing and restriction in jaw movement perceived by the patients as well as the $p$-values of significance tests

\begin{tabular}{|c|c|c|c|c|c|c|}
\hline \multirow{2}{*}{ Time point } & \multirow{2}{*}{ Variable } & \multicolumn{2}{|c|}{$\operatorname{LG}(n=16)$} & \multicolumn{2}{|c|}{$\mathrm{PG}(n=16)$} & \multirow{2}{*}{$\frac{\text { LG vs PG }}{p \text {-value }^{\dagger}}$} \\
\hline & & Me & IQR & Me & IQR & \\
\hline \multirow{2}{*}{$\mathrm{T} 1$} & difficulty in swallowing & 2 & $1-2$ & 2 & $1-3.75$ & 0.236 \\
\hline & restriction in jaw movement & 2 & $1-3$ & 2 & $1-3$ & 0.877 \\
\hline \multirow{2}{*}{$\mathrm{T} 2$} & difficulty in swallowing & 0 & $0-1$ & 0 & $0-1$ & 0.687 \\
\hline & restriction in jaw movement & 0 & $0-2$ & 1 & $0-1.5$ & 0.427 \\
\hline \multirow{2}{*}{ T3 } & difficulty in swallowing & 0 & $0-0$ & 0 & $0-1$ & 0.422 \\
\hline & restriction in jaw movement & 0 & $0-0.5$ & 0 & $0-1$ & 0.630 \\
\hline \multirow{2}{*}{ T4 } & difficulty in swallowing & 0 & $0-0$ & 0 & $0-0$ & 0.551 \\
\hline & restriction in jaw movement & 0 & $0-0$ & 0 & $0-0$ & 0.632 \\
\hline
\end{tabular}

${ }^{\dagger}$ Mann-Whitney $U$ test.

\section{Analgesic consumption}

The amount of paracetamol consumption was low in both groups, with a maximum of $1 \mathrm{~g}$ at $\mathrm{T} 1$, and did not differ significantly between both groups (Table 4).

\section{Satisfaction and acceptance}

The patients reported high levels of satisfaction in both groups; the median value for LG was 10 (interquartile range (IQR): 8.25-10) and it was 9 (IQR: 7-10) for PG, with no significant differences between the 2 groups. A great proportion of patients in both groups (i.e., 87.5\% in LG and 81.3\% in PG) reported that they would advise a friend to undergo the same treatment and the difference in proportions between both groups was insignificant $(p=0.626)$. Additionally, the majority of patients in both groups (i.e., 75\% in LG and 68.8\% in PG) found that the extraction of premolars was more disturbing than flapless corticotomy and the difference in proportions between both groups was insignificant $(p=0.828)$.

\section{Changes within groups}

The results of Friedman's test showed that there were significant differences between the 4 evaluated time points regarding the levels of pain $(p<0.001, p<0.001)$, discomfort $(p<0.001, p<0.001)$, swelling $(p<0.001, p<0.001)$, difficulty in chewing $(p=0.001, p=0.001)$, difficulty in swallowing $(p<0.001, p<0.001)$, and restriction in jaw movement $(p=0.001, p=0.001)$ for LG and PG, respectively. There were no significant differences in analgesic consumption between the 4 evaluated time points within LG $(p=0.164)$ whereas the differences were significant within PG $(p=0.002)$. Post-hoc pairwise comparisons are demonstrated in Tables 5 and 6.

Table 4. Descriptive statistics of analgesic consumption as well as the $p$-values of significance tests

\begin{tabular}{|c|c|c|c|c|c|c|c|c|c|c|}
\hline \multirow{3}{*}{ Time point } & \multicolumn{5}{|c|}{ Amount of paracetamol [g] } & \multicolumn{5}{|c|}{ Patients taking/not taking analgesics $n(\%)$} \\
\hline & \multicolumn{2}{|c|}{$\operatorname{LG}(n=16)$} & \multicolumn{2}{|c|}{ PG $(n=16)$} & \multirow{2}{*}{$p$-value ${ }^{\dagger}$} & \multicolumn{2}{|c|}{$\operatorname{LG}(n=16)$} & \multicolumn{2}{|c|}{$\mathrm{PG}(n=16)$} & \multirow{2}{*}{$p$-value ${ }^{\dagger \dagger}$} \\
\hline & Me & $I Q R$ & Me & $I Q R$ & & yes & no & yes & no & \\
\hline $\mathrm{T} 1$ & 0 & $0-0.5$ & 0.5 & $0-1$ & 0.137 & $5(31.3)$ & $11(68.8)$ & $9(56.3)$ & $7(43.8)$ & 0.154 \\
\hline $\mathrm{T} 2$ & 0 & $0-0$ & 0 & $0-0.37$ & 0.695 & $3(18.8)$ & $13(81.3)$ & $4(25.0)$ & $12(75.0)$ & 0.669 \\
\hline $\mathrm{T} 3$ & 0 & $0-0$ & 0 & $0-0$ & 0.551 & $1(6.3)$ & $15(93.8)$ & $2(12.5)$ & $14(87.5)$ & 0.544 \\
\hline T4 & 0 & $0-0$ & 0 & $0-0$ & 0.317 & $1(6.3)$ & 15 (93.8) & $0(0)$ & $16(100)$ & 0.310 \\
\hline
\end{tabular}

${ }^{\dagger}$ Mann-Whitney $U$ test; ${ }^{+\dagger} X^{2}$ test. Question 11: Have you used analgesics for pain from your teeth or jaws? If yes, what dosage did you use?

Table 5. Results of the significance tests of pairwise comparisons between the 4 evaluated time points for patient-centered outcomes in the laser-assisted flapless corticotomy group (LG)

\begin{tabular}{|c|l|c|c|c|c|c|} 
Time points & Pain & Discomfort & Swelling & Difficulty in chewing & Difficulty in swallowing & Restriction in jaw movement \\
\hline T1-T2 & $0.003^{*}$ & $0.001^{*}$ & 0.017 & $0.001^{*}$ & 0.033 & 0.051 \\
T1-T3 & $0.001^{*}$ & $<0.001^{*}$ & $0.001^{*}$ & $<0.001^{*}$ & $0.003^{*}$ & $0.003^{*}$ \\
T1-T4 & $0.001^{*}$ & $<0.001^{*}$ & $0.001^{*}$ & $<0.001^{*}$ & $0.002^{*}$ & $0.002^{*}$ \\
T2-T3 & 0.097 & $0.006^{*}$ & 0.018 & $0.133^{*}$ & 0.129 & 0.071 \\
T2-T4 & $0.006^{*}$ & $0.001^{*}$ & $0.007^{*}$ & 0.019 & 0.066 & 0.068 \\
T3-T4 & 0.038 & 0.103 & 0.257 & 0.059 & 0.317 & 0.040 \\
\hline
\end{tabular}

The Wilcoxon signed-ranks tests were employed for pairwise comparisons, with the Bonferroni adjustment of alpha level (i.e., $0.05 / 6=0.008$ )

* $p<0.008$ (significant difference). 
Table 6. Results of the significance tests of pairwise comparisons between the 4 evaluated time points for patient-centered outcomes in the piezocision group $(\mathrm{PG})$

\begin{tabular}{|c|c|c|c|c|c|c|c|}
\hline Time points & Pain & Discomfort & Swelling & Difficulty in chewing & Difficulty in swallowing & Restriction in jaw movement & Analgesic consumption \\
\hline T1-T2 & $<0.001^{*}$ & $0.001^{*}$ & $0.004^{*}$ & $0.001^{*}$ & $0.003^{*}$ & 0.026 & 0.041 \\
T1-T3 & $<0.001^{*}$ & $<0.001^{*}$ & $0.001^{*}$ & $0.001^{*}$ & $0.002^{*}$ & $0.005^{*}$ & 0.008 \\
T1-T4 & $<0.001^{*}$ & $<0.001^{*}$ & $0.000^{*}$ & $<0.001^{*}$ & $0.001^{*}$ & $0.001^{*}$ & $0.007^{*}$ \\
T2-T3 & 0.015 & $0.001^{*}$ & $0.003^{*}$ & 0.039 & 0.236 & 0.038 & 0.180 \\
T2-T4 & $0.003^{*}$ & $0.001^{*}$ & $0.001^{*}$ & $0.003^{*}$ & 0.039 & 0.018 & 0.059 \\
T3-T4 & 0.046 & 0.130 & 0.096 & 0.101 & 0.180 & 0.366 & 0.157 \\
\hline
\end{tabular}

The Wilcoxon signed-ranks tests were employed for pairwise comparisons, with the Bonferroni adjustment of alpha level (i.e., $0.05 / 6=0.008$ ). ${ }^{*} p<0.008$ (significant difference).

\section{Discussion}

According to our knowledge, this is the first trial in the literature comparing patient-centered outcomes during upper canine retraction associated with piezocision vs LAFC. There were no significant differences between both groups regarding age and gender. Therefore, both groups were homogeneous and comparable. The numerical rating scale was used to answer most of the questions, since this scale has been shown to possess high reliability in comparison with the visual analog scale (VAS). ${ }^{17-19}$ The patients' responses were first taken 1 day after flapless corticotomy treatment in both groups. Immediate recording of pain following the intervention was deemed unsuitable due to the possible interference of pain relief resulting from the use of local anesthesia. The main finding was that patients in LG experienced significantly less pain and discomfort at T1 as compared to PG.

The levels of pain and discomfort at the experimental sides were significantly higher than those at the control sides in both groups at T1. These slightly higher levels can be explained by the trauma of the gingiva and the alveolar bone during the implementation of LAFC and piezocision. The levels of pain and discomfort were significantly lower in LG as compared to PG and this could be attributed to the fact that soft tissue incisions in PG were performed with a blade whereas in LG, an Er:YAG laser was used to perform both soft tissue and alveolar bone perforations, which is characterized by less painful cuts in addition to little postoperative pain..$^{20,21}$ One of the theories that explains this is that protein coagulation caused by laser cutting seals the sensory nerve endings, and thus relieves the sensation of pain. ${ }^{22}$ Furthermore, the fiber tip used in LG was in the non-contact mode; thus, no mechanical pressure was applied to the gingival tissue, as opposed to the traditional blade used in PG.

A significant reduction in pain and discomfort levels was observed after 1 day following the surgical intervention in both groups. Therefore, the differences between the experimental and the control sides were no longer significant. This could be explained by rapid recovery associated with the use of a piezosurgery $\mathrm{knife}^{23}$ and an Er:YAG laser. ${ }^{24}$ Consequently, analgesic consumption was low in both groups. There are no trials in the literature evaluating pain and discomfort while accelerating canine retraction in conjunction with piezocision or LAFC; therefore, a direct comparison with other trials is not straightforward. The levels of pain and discomfort associated with micro-osteoperforations accomplished with the Propel ${ }^{\mathbb{B}}$ device were not significant 1 day after canine retraction in Alikhani et al's trial, ${ }^{25}$ but in the present trial, they were significant. This difference between the 2 studies could be explained by different designs of the surgical intervention as well as different devices employed.

High levels of swelling perception were observed at the experimental sides at $\mathrm{T} 1$ for both techniques, which could be attributed to edema resulting from surgical trauma that is associated with such procedures. Additionally, difficulty in chewing was significantly higher at the experimental sides than at the control sides in both groups at T1, and this could be correlated with the encountered pain and discomfort following the surgical intervention. The levels of difficulty in swallowing and restriction in jaw movement were low in both groups, with no significant differences. This can be explained by the conservative nature of the surgical intervention in both groups.

Patients reported high levels of satisfaction and acceptance of the surgical intervention, with negligible differences between both groups. This might be due to the minimally invasive nature of piezocision and LAFC, as they did not require flap raising or suturing like conventional corticotomy. Another factor could be related to the use of innovated tools, which resulted in less trauma and morbidity as compared to the traditional use of surgical burs. These findings are in line with those of Uribe et al. ${ }^{26}$ and Charavet et al., ${ }^{27}$ who found that high levels of satisfaction were achieved in patients subjected to piezocision during the leveling and alignment of their teeth. In the present study, the majority of patients in both groups indicated that the extraction of the upper premolars was a more disturbing experience than flapless corticotomy. This could have resulted from the fact that the extraction 
of the premolars was performed bilaterally whereas piezocision/LAFC was conducted only at one side of the upper arch. Another factor is the conservative nature of flapless corticotomy employed in this trial.

One of the limitations of this study is its split-mouth design. The patients experienced oral pain or discomfort only from one side of the mouth, which would not reflect the actual picture if the surgical intervention had been carried out at both sides. Therefore, the results of this study cannot be generalized unless a complete procedure mimicking the actual scenario in the daily practice is carried out for patients undergoing canine retraction in the context of orthodontic treatment.

\section{Conclusions}

Both piezocision and LAFC were associated with significantly high levels of pain, discomfort, swelling, and difficulty in chewing at 1 day following the intervention. Laser-assisted flapless corticotomy was associated with significantly lower levels of pain and discomfort than piezocision. The levels of pain, discomfort, swelling, eating difficulty, and jaw movement restriction dramatically decreased $24 \mathrm{~h}$ after LAFC and piezocision. Both piezocision and LAFC were associated with high levels of satisfaction and acceptance.

\section{ORCID iDs}

Alaa Mohammad Haytham Alfawal

(D) https://orcid.org/0000-0002-6732-0645

Mohammad Younis Hajeer (1) https://orcid.org/0000-0003-0640-1297

Mowaffak Ahmad Ajaj (D) https://orcid.org/0000-0002-8602-6986

Omar Hamadah (1) https://orcid.org/0000-0002-2308-0547

Bassel Brad (1) https://orcid.org/0000-0002-2428-5499

Youssef Latifeh (10) https://orcid.org/0000-0003-2832-1212

\section{References}

1. Rosvall MD, Fields HW, Ziuchkovski J, Rosenstiel SF, Johnston WM. Attractiveness, acceptability, and value of orthodontic appliances. Am J Orthod Dentofacial Orthop. 2009;135(3):276.e1-e12;discussion 276-277.

2. Wilcko WM, Wilcko T, Bouquot JE, Ferguson DJ. Rapid orthodontics with alveolar reshaping: Two case reports of decrowding. Int J Periodontics Restorative Dent. 2001;21(1):9-19.

3. Wilcko MT, Wilcko WM, Bissada NF. An evidence-based analysis of periodontally accelerated orthodontic and osteogenic techniques: A synthesis of scientific perspectives. Semin Orthod. 2008;14(4):305-316.

4. Hassan AH, Al-Fraidi AA, Al-Saeed SH. Corticotomy-assisted orthodontic treatment: Review. Open Dent J. 2010;4:159-164.

5. Dibart S, Sebaoun JD, Surmenian J. Piezocision: A minimally invasive, periodontally accelerated orthodontic tooth movement procedure. Compend Contin Educ Dent. 2009;30(6):342-344,346,348-350.

6. Salman LH, Ali FA. Acceleration of canine movement by laser assisted flapless corticotomy (An innovative approach in clinical orthodontics). J Baghdad Coll Dent. 2014;26(3):133-137.

7. Seifi M, Younessian F, Ameli N. The innovated laser assisted flapless corticotomy to enhance orthodontic tooth movement. J Lasers Med Sci. 2012;3(1):20-25.

8. Nimeri G, Kau CH, Abou-Kheir NS, Corona R. Acceleration of tooth movement during orthodontic treatment - a frontier in orthodontics. Prog Orthod. 2013;14:42.
9. Krishnan V. Orthodontic pain: From causes to management - a review. Eur J Orthod. 2007;29(2):170-179.

10. Gibreal O, Hajeer MY, Brad B. Evaluation of the levels of pain and discomfort of piezocision-assisted flapless corticotomy when treating severely crowded lower anterior teeth: A single-center, randomized controlled clinical trial. BMC Oral Health. 2019;19(1):57.

11. Figueiredo DSF, Houara RG, Cid-Pinto LMdM, et al. Effects of piezocision in orthodontic tooth movement: A systematic review of comparative studies. J Clin Exp Dent. 2019;11(11):e1078-e1092.

12. Fu T, Liu S, Zhao H, Cao M, Zhang R. Effectiveness and safety of minimally invasive orthodontic tooth movement acceleration: A systematic review and meta-analysis. J Dent Res. 2019;98(13):1469-1479.

13. Alfawal AMH, Hajeer MY, Ajaj MA, Hamadah O, Brad B. Effectiveness of minimally invasive surgical procedures in the acceleration of tooth movement: A systematic review and meta-analysis. Prog Orthod. 2016;17(1):33.

14. Vercellotti T, Podesta A. Orthodontic microsurgery: A new surgically guided technique for dental movement. Int J Periodontics Restorative Dent. 2007;27(4):325-331.

15. Al-Naoum F, Al-Sabbagh R, Al-Jundi A. Periodontally accelerated osteogenic non-extraction orthodontics versus conventional extraction-based orthodontics in dental decrowding: A randomized controlled trial. Int Arab J Dent. 2015;6(1):9-19.

16. http://www.ada.org/en/member-center/oral-health-topics/antibiotic-prophylaxis. Accessed on August 7, 2019.

17. Cook KF, Dunn W, Griffith JW, et al. Pain assessment using the NIH toolbox. Neurology. 2013;80(11 Suppl 3):S49-S53.

18. Hollen PJ, Gralla RJ, Kris MG, McCoy S, Donaldson GW, Moinpour CM. A comparison of visual analogue and numerical rating scale formats for the lung cancer symptom scale (LCSS): Does format affect patient ratings of symptoms and quality of life? Qual Life Res. 2005;14(3):837-847.

19. Phan NQ, Blome C, Fritz F, et al. Assessment of pruritus intensity: Prospective study on validity and reliability of the visual analogue scale, numerical rating scale and verbal rating scale in 471 patients with chronic pruritus. Acta Derm Venereol. 2012;92(5):502-507.

20. Arnabat-Domínguez J, España-Tost AJ, Berini-Aytés L, Gay-Escoda C. Erbium:YAG laser application in the second phase of implant surgery: A pilot study in 20 patients. Int J Oral Maxillofac Implants. 2003;18(1):104-112.

21. Zeredo JL, Sasaki KM, Yozgatian JH, Okada Y. Toda K. Comparison of jaw-opening reflexes evoked by Er:YAG laser versus scalpel incisions in rats. Oral Surg Oral Med Oral Pathol Oral Radiol Endod. 2005;100(1):31-35.

22. Romaniello A, lannetti GD, Truini A, Cruccu G. Trigeminal responses to laser stimuli. Neurophysiol Clin. 2003;33(6):315-324.

23. Vercellotti T, Nevins ML, Kim DM, et al. Osseous response following resective therapy with piezosurgery. Int J Periodontics Restorative Dent. 2005;25(6):543-549.

24. Stübinger S. Advances in bone surgery: The Er:YAG laser in oral surgery and implant dentistry. Clin Cosmet Investig Dent. 2010;2:47-62.

25. Alikhani M, Raptis M, Zoldan B, et al. Effect of micro-osteoperforations on the rate of tooth movement. Am J Orthod Dentofacial Orthop. 2013;144(5):639-648.

26. Uribe F, Davoody L, Mehr R, et al. Efficiency of piezotome-corticision assisted orthodontics in alleviating mandibular anterior crowding - a randomized clinical trial. Eur J Orthod. 2017;39(6):595-600.

27. Charavet $C$, Lecloux $G$, Bruwier $A$, et al. Localized piezoelectric alveolar decortication for orthodontic treatment in adults: A randomized controlled trial. J Dent Res. 2016;95(9):1003-1009. 
